\title{
Improving the cold flow properties of biodiesel from waste cooking oil by ternary blending with bio-based alcohols and diesel from direct coal liquefaction
}

\author{
Yuan Xue ${ }^{1}$, Lihong Wang ${ }^{2}$, Hualin Lin $^{1}$, Sheng Han ${ }^{1}$, and Shiyou Zheng ${ }^{3}$ \\ ${ }^{1}$ Shanghai Institute of Technology \\ ${ }^{2}$ Shanghai Urban Construction Vocational College \\ ${ }^{3}$ University of Shanghai for Science and Technology
}

April 13, 2021

\begin{abstract}
The utilization and popularization of biodiesel are always limited by its poor cold flow properties. Both bio-based alcohol and diesel from direct coal liquefaction (DDCL) has potential to enhance the cold flow properties of biodiesel. Ternary blends of waste cooking oil biodiesel (BWCO) with DDCL and bio-based ethanol (ET) or 1-butanol (BT) for improving the cold flow properties of biodiesel. The pour point (PP), cold filter plugging point (CFPP), and cloud point (CP) of BWCO-ET, BWCO-BT, and BWCO-DDCL binary blends, and BWCO-ET-DDCL and BWCO-BT-DDCL ternary blends were comparatively assessed. Ternary phase diagrams were also applied into analyze the blending effect of the three components on the cold flow properties of biodiesel. Results showed that both DDCL, ET and BT can remarkably enhance the cold flow properties of BWCO. BT and DDCL presented a better synergistic depression effect. For ternary blends in 20:10:70 blending ratio, BWCO-BT-DDCL exhibited the lowest PP, CFPP, and $\mathrm{CP}$ of $-23{ }^{\circ} \mathrm{C},-19 \operatorname{degC}$, and $-17 \operatorname{deg} \mathrm{C}$, respectively. The crystallization behavior and crystal morphology of blended fuels are also observed via a polarizing optical microscope, and find that DDCL together with BT in biodiesel can effectively retard the aggregation of large crystals and inhibit crystals growth.
\end{abstract}

Improving the cold flow properties of biodiesel from waste cooking oil by ternary blending with bio-based alcohols and diesel from direct coal liquefaction

Yuan Xue ${ }^{1,2, *}$, Lihong Wang ${ }^{3}$, Hualin $\operatorname{Lin}^{2}$, Sheng $\operatorname{Han}^{1,2,{ }^{*}}$, Shiyou Zheng, ${ }^{2, *}$

${ }^{1}$ School of Materials Science and Engineering, University of Shanghai for Science and Technology, Shanghai, 200093, China

${ }^{2}$ School of Chemical and Environmental Engineering, Shanghai Institute of Technology, Shanghai 201418, China

${ }^{3}$ Department of Science and Technology, Shanghai Urban Construction Vocational College, Shanghai 201415, China

* Corresponding author: Fax: +86-021-60873565, Tel: +86-02160873685; Email address: sit_xueyuan@163.com (Yuan Xue),syzheng@usst.edu.cn (Shiyou Zheng), hansheng654321@sina.com (Sheng Han)

Abstract:The utilization and popularization of biodiesel are always limited by its poor cold flow properties. Both bio-based alcohol and diesel from direct coal liquefaction (DDCL) has potential to enhance the cold flow properties of biodiesel. Ternary blends of waste cooking oil biodiesel (BWCO) with DDCL and bio-based ethanol (ET) or 1-butanol (BT) for improving the cold flow properties of biodiesel. The pour point (PP), cold filter plugging point (CFPP), and cloud point (CP) of BWCO-ET, BWCO-BT, and BWCO-DDCL 
binary blends, and BWCO-ET-DDCL and BWCO-BT-DDCL ternary blends were comparatively assessed. Ternary phase diagrams were also applied into analyze the blending effect of the three components on the cold flow properties of biodiesel. Results showed that both DDCL, ET and BT can remarkably enhance the cold flow properties of BWCO. BT and DDCL presented a better synergistic depression effect. For ternary blends in 20:10:70 blending ratio, BWCO-BT-DDCL exhibited the lowest PP, CFPP, and CP of $-23{ }^{\circ} \mathrm{C},-19$ $\operatorname{deg} \mathrm{C}$, and $-17 \operatorname{deg} \mathrm{C}$, respectively. The crystallization behavior and crystal morphology of blended fuels are also observed via a polarizing optical microscope, and find that DDCL together with BT in biodiesel can effectively retard the aggregation of large crystals and inhibit crystals growth.

Keywords: waste cooking oil biodiesel; ternary blends; cold flow properties; bio-based alcohol; diesel from direct coal liquefaction

\section{Introduction}

With the rapid growth of the population and the economy, the worsening environmental pollution and the growing energy deficit have become a major concern in the world. The existing petrodiesel is always limited by its diminishing reserves and environmental hazards [1]. Among the proposed alternatives, biodiesel for diesel engines has attracted the increasing attention of scholars over the past decade because of the advantages of renewability, biodegradability, nonflammability, nontoxicity, and environmental friendliness $[2,3]$. One of the major technical obstacles that hinders the developments and application of biodiesel fuels is their poor low-temperature flow properties, which may cause blockage of the oil pipelines and filter because of the crystallization of the saturated fatty acid methyl esters with high melting points in biodiesel fuels [47]. Nevertheless, many methods can be used to mitigate this problem, such as modifying structures [8, 9], winterization [10, 11], adding pour point depressants [12-14], and blending with diesel [15, 16].

In all these methods, blending biodiesel with fossil diesel is the simplest, most efficient, and indispensable technique used by manufacturers and researchers to enhance the low-temperature flow properties of biodiesel, and maximize the profits from various fuel products. In China, the coals are the major source of energy fuels, and occupy approximately $92.4 \%$ of the total fossil energy reserves of the country [17, 18]. Diesel from direct coal liquefaction (DDCL) is a value-added diesel fuel that is directly transformed from solid coal via hydrogenation liquefaction reaction under high temperature, high pressure, and suitable catalyst [15, 18]. In comparison, DDCL has more excellent low-temperature flow properties than petroleum diesel (PD), and it is a good substitute for enhancing the low-temperature performance of biodiesel in coal-rich countries like China $[15,19,20]$.

In our previous study [15], 0\# PD and DDCL blended together with the waste cooking oil biodiesel (BWCO), and exhibited positive effects on improving the pour point (PP), cold filter plugging point (CFPP), and cloud point (CP) of BWCO. For ternary blends of BWCO-PD-DDCL containing $20 \mathrm{vol} \%$ BWCO and 10 vol.\% to 40 vol.\% PD, the CFPP was relatively lower than those of binary biodiesel blends (20 vol.\% BWCO). Nevertheless, the limited petroleum resources and the environmental pollution always restrict the concoctions of petrodiesel and biodiesel. Alcohols, such as ethanol (ET) and 1-butanol (BT), are primarily bio-based renewable energy because they are derived from the fermentation of renewable biomass [21-23]. Many researchers have investigated the effect of blending alcohols with biodiesel or diesel on the cold flow properties because of their relatively lower freezing points [14, 24]. Hence, replacing the petrodiesel with biobased alcohols in ternary blends with biodiesel and DDCL to enhance the low-temperature flow properties of biodiesel is extremely possible. However, there is a paucity of technical data in previous reports regarding the effect of ternary bends of biodiesel with bio-based alcohols and DDCL on the low-temperature flow properties of BWCO.

Waste cooking oil (WCO) is one of the potential raw materials for producing biodiesel because of its low-cost, extensive source and environmental friendliness [25-27]. In this work, BWCO was produced and compared with ASTM D6751 standard [28] and EN 14214. The bio-based ET and BT were first introduced into BWCO together with DDCL to improve the low-temperature flow properties of biodiesel. New data presenting the blending effect of those three components on the PP, CFPP and CP of BWCO-ET-DDCL and BWCO- 
BT-DDCL ternary blends were comparatively reported by ternary phase diagrams. In particular crystal morphology and crystallization behavior were explored by using polarized optical microscope (POM).

\section{Experimental}

\subsection{Materials}

The refined WCO was obtained from Shanghai Zhongqi Environment Technology Co., Ltd. DDCL was obtained from Shanghai Institute of China SH Coal to Liquid and Chemical Co., Ltd. Ethanol (ET) and 1-butanol (BT) with purity of [?] $99.7 \%$ was purchased from Shanghai Titan Technology Co., Ltd. (China). All other chemicals and reagents were analytical grade and obtained from Adamas-beta ${ }^{(\mathrm{r})}$ Reagent Co., Ltd. (Shanghai).

In addition, BWCO used in this paper was produced by the alkali-catalyzed transesterification of WCO with methanol in our laboratory [12].

\subsection{Methods}

\subsubsection{GC-MS analysis}

Shimadzu QP 2010/Plus GC-MS were conducted on the composition analysis of BWCO and DDCL on the basis of the MS data to the NIST library. The GC operating conditions are as follows: RXi-5Sil MS (30 $\mathrm{m} \mathrm{x}$ $0.25 \mathrm{~mm} \times 0.25 \mu \mathrm{m}$ ); capillary column temperature of BWCO was first increased by $5{ }^{\circ} \mathrm{C} / \mathrm{min}$ from 80 to 160 ${ }^{\circ} \mathrm{C}$, followed by $3{ }^{\circ} \mathrm{C} / \mathrm{min}$ from 160 to $240{ }^{\circ} \mathrm{C}$; capillary column temperature of DDCL was first increased by $0.5{ }^{\circ} \mathrm{C} / \mathrm{min}$ from 50 to $70{ }^{\circ} \mathrm{C}$, and followed by $5{ }^{\circ} \mathrm{C} / \mathrm{min}$ from 70 to $250{ }^{\circ} \mathrm{C}$; interface temperature of $\mathrm{BWCO}$ and DDCL were set to be 300 and $270{ }^{\circ} \mathrm{C}$, respectively; injection temperatures and volume were $270{ }^{\circ} \mathrm{C}$ and $1.0 \mu \mathrm{L}$; and the gas flow rates $(99.9 \%$ helium) were $1.0 \mathrm{~mL} / \mathrm{min}$. The GC-MS analysis results of BWCO and DDCL are presented in Table 1 and Table 2, respectively.

Figure 1. Total ion chromatograms of BWCO.

Table 1 Compositions of BWCO.

\begin{tabular}{|c|c|c|c|c|}
\hline No. & $\begin{array}{l}\text { Retention time } \\
(\min )\end{array}$ & $\begin{array}{l}\text { Name of fatty acid } \\
\text { methyl ester } \\
\text { (FAME) }\end{array}$ & Corresponding acid & Total (wt.\%) \\
\hline 1 & 26.233 & $\begin{array}{l}\text { Methyl } \\
\text { tetradecanoate }\end{array}$ & C14:0 & 0.81 \\
\hline 2 & 32.548 & $\begin{array}{l}\text { Methyl } \\
\text { 9-hexadecenoate }\end{array}$ & $\mathrm{C} 16: 1$ & 1.00 \\
\hline 3 & 33.556 & $\begin{array}{l}\text { Methyl } \\
\text { hexadecanoate }\end{array}$ & C16:0 & 17.44 \\
\hline 4 & 39.040 & Methyl linoleate & $\mathrm{C} 18: 2$ & 35.97 \\
\hline 5 & 39.515 & Methyl oleate & C18:1 & 36.44 \\
\hline 6 & 40.127 & $\begin{array}{l}\text { Methyl } \\
\text { octadecanoate }\end{array}$ & $\mathrm{C} 18: 0$ & 7.52 \\
\hline
\end{tabular}

Figure 2. Total ion chromatograms of DDCL

Table 2 Compositions of DDCL

\begin{tabular}{|c|c|c|c|c|c|c|c|}
\hline No. & Retention time (min) & Component & Total (wt.\%) & No. & Retention time (min) & Component & Total (wt.\%) \\
\hline 1 & 6.230 & & 0.67 & 2 & 6.763 & & 0.47 \\
\hline 3 & 7.079 & & 0.87 & 4 & 7.710 & & 0.41 \\
\hline 5 & 8.279 & & 2.32 & 6 & 9.805 & & 1.65 \\
\hline
\end{tabular}




\begin{tabular}{|c|c|c|c|c|c|c|c|}
\hline No. & Retention time $(\mathrm{min})$ & Component & Total (wt.\%) & No. & Retention time $(\mathrm{min})$ & Component & Total (wt.\%) \\
\hline 7 & 11.937 & & 0.94 & 8 & 12.202 & & 3.77 \\
\hline 9 & 12.581 & & 0.68 & 10 & 12.861 & & 0.59 \\
\hline 11 & 13.343 & & 0.45 & 12 & 13.627 & & 2.16 \\
\hline 13 & 13.979 & & 0.95 & 14 & 14.377 & & 0.49 \\
\hline 15 & 14.661 & & 1.01 & 16 & 16.089 & & 0.72 \\
\hline 17 & 16.427 & & 2.11 & 18 & 16.989 & & 2.84 \\
\hline 19 & 17.241 & & 1.23 & 20 & 17.696 & & 0.80 \\
\hline 21 & 18.570 & & 7.24 & 22 & 18.945 & & 0.94 \\
\hline 23 & 20.007 & & 0.86 & 24 & 22.941 & & 0.77 \\
\hline 25 & 24.169 & & 2.20 & 26 & 26.181 & & 14.33 \\
\hline 27 & 28.395 & & 3.74 & 28 & 29.690 & & 2.90 \\
\hline 29 & 44.230 & & 1.91 & 30 & 46.445 & & 1.43 \\
\hline 31 & 52.072 & & 1.37 & 32 & 52.995 & & 0.79 \\
\hline 33 & 53.992 & & 1.45 & 34 & 54.715 & & 3.41 \\
\hline 35 & 55.366 & & 1.95 & 36 & 55.521 & & 0.53 \\
\hline 37 & 55.646 & & 0.37 & 38 & 56.501 & & 2.97 \\
\hline 39 & 57.024 & & 0.48 & 40 & 57.644 & & 0.41 \\
\hline 41 & 58.346 & & 0.99 & 42 & 58.799 & & 0.56 \\
\hline 43 & 59.112 & & 2.82 & 44 & 59.594 & & 0.77 \\
\hline 45 & 59.961 & & 1.44 & 46 & 61.188 & & 0.94 \\
\hline 47 & 61.586 & & 0.91 & 48 & 62.371 & & 2.03 \\
\hline 49 & 65.136 & & 1.18 & 50 & 67.622 & & 0.58 \\
\hline
\end{tabular}

\subsubsection{Preparation of biodiesel blends}

Multicomponent biodiesel blends, such as BWCO-DDCL, BWCO-ET, BWCO-BT, BWCO-ET-DDCL and BWCO-BT-DDCL, were blended using the homogenizer (500rpm, 15 minutes) at a room temperature to ensure that the mixtures were mixed homogeneously. Finally, the fuel blends were stored in plastic bottles for the following determination.

\subsubsection{Fuel properties determination}

$\mathrm{CP}$, CFPP, and PP are used to characterize the low-temperature flow properties of biodiesel fuels [19]. CP refers to the highest temperature where the cloudy crystals appeared in the sample fuel. PP corresponds to the lowest temperature where the sample fuels lose their fluid ability after cooling at a prescribed rate. CFPP is termed as the lowest temperature where a prescribed volume $(20 \mathrm{~mL})$ of sample fuel is no longer passing safely through the wire mesh filter within one minute. The PP, CFPP and CP of sample fuels were measured by using the SYP1022-2 multi-functional low-temperature tester (Shanghai Boli Instrument Co., Ltd., China) in accordance with the standard methods of ASTM D6371, ASTM D2500, and ASTM D97 [29-31], respectively. Additionally, other fuel properties, such as acid value (AV), oxidation stability (OS), flash point (FP), density $(\rho)$ and kinematic viscosity $(U)$, were determined according to the standard methods that listed in Table 3.

Table 3 The selected standards and physico-chemical properties of BWCO and DDCL.

\begin{tabular}{llllll}
\hline Properties (unit) & Test methods & ASTM D6751 & EN 14214 & Diesel fuels & Diesel fuels \\
\hline & & & & BWCO & DDCL \\
CP $\left({ }^{\circ} \mathrm{C}\right)$ & ASTM D2500 & report & $-{ }^{a}$ & 6 & -41 \\
CFPP $\left({ }^{\circ} \mathrm{C}\right)$ & ASTM D6371 & - & - & 5 & -49 \\
PP $\left({ }^{\circ} \mathrm{C}\right)$ & ASTM D97 & - & - & 4 & -62 \\
OS $\left(110{ }^{\circ} \mathrm{C}, \mathrm{h}\right)$ & EN 14112 & min 3.0 & min 6.0 & 4.8 & 27
\end{tabular}




\begin{tabular}{llllll}
\hline Properties (unit) & Test methods & ASTM D6751 & EN 14214 & Diesel fuels & Diesel fuels \\
\hline FP $\left({ }^{\circ} \mathrm{C}\right)$ & ASTM D93 & $\min 93$ & $\operatorname{min~101}$ & 153 & 69 \\
$\mathrm{AV}(\mathrm{mg}, \mathrm{KOH} / \mathrm{g})$ & ASTM D445 & $\max 0.50$ & $\max 0.50$ & 0.37 & 0.032 \\
$\mathrm{P}\left(15{ }^{\circ} \mathrm{C}, \mathrm{g} / \mathrm{cm}^{3}\right)$ & ASTM D664 & - & $860-890$ & 888.9 & 865.6 \\
$\mathrm{u}\left(40{ }^{\circ} \mathrm{C}, \mathrm{mm}^{2} / \mathrm{s}\right)$ & ASTM D1298 & $1.9-6.0$ & $3.5-6.0$ & 4.06 & 1.88 \\
\hline
\end{tabular}

$\mathrm{BWCO}=$ waste cooking oil biodiesel, $\mathrm{DDCL}=$ diesel from direct coal liquefaction, $\mathrm{CP}=$ cloud point, $\mathrm{CFPP}$ $=$ cold filter plugging point, $\mathrm{PP}=$ pour point, $\mathrm{AV}=$ acid value, $\mathrm{OS}=$ oxidation stability, $\mathrm{FP}=$ flash point, $\rho=$ density, $u=$ kinematic viscosity.

${ }^{\text {a }}$ Not specified.

\subsubsection{Polarizing optical microscope (POM)}

A DM2500P polarizing optical microscope (Leica Microsystems, Wetzlar, Germany) equipped with a Leica DFC420C digital camera was used for observing the wax crystal morphology and crystallization behavior of sample fuels. A drop of samples was putted on a slide, and initially hold at $30{ }^{\circ} \mathrm{C}$ for $3 \mathrm{~min}$ to eliminate all the crystal memory and subsequently cooled under a fixed cooling rate $\left(0.8^{\circ} \mathrm{C} / \mathrm{min}\right)$ down to $-60 \mathrm{degC}$ using the liquid nitrogen, and the micrographs were captured in $1 \operatorname{deg} \mathrm{C}$ increments under a magnification of 100x.

\section{Results and discussion}

\subsection{Compositions and fuel properties of BWCO, DDCL, ET and BT}

The total ion chromatogram and the fatty acid methyl ester (FAME) compositions of the neat BWCO are shown in Figure 1 and Table 1. The BWCO is composed of FAMEs with different carbon chains and saturated compositions. As shown in Figure 1 and Table 1, although the unsaturated FAMEs (73.41 wt.\%) in the prepared BWCO are more than saturated FAMEs, the relatively higher content of saturated esters (25.77 wt.\%) always resulted in the weaker low-temperature fluidity of BWCO. Table 3 shows that the PP, CFPP, and $\mathrm{CP}$ of BWCO are $4 \mathrm{degC}, 5 \mathrm{degC}$, and $6 \mathrm{degC}$, respectively, and other fuel properties, such as acid value, oxidation stability, flash point, density, and kinematic viscosity are within the ASTM D6751 and EN 14214 limits.

The compositions and fuel properties of DDCL are differ from that of BWCO. Figure 2 and Table 2 show the total ion chromatogram and compositions of DDCL. DDCL is a liquid fuel direct obtained from solid coal liquefaction reaction and mainly consists of hydrocarbons, cycloalkanes, alkanes, and alkenes [15, 18]. Thus, DDCL exerted better low-temperature flow properties than biodiesel due to their lower melting points. The CP, CFPP and PP of DDCL reached $-41 \operatorname{degC},-49 \operatorname{deg} \mathrm{C}$ and $-62 \operatorname{deg} \mathrm{C}$, respectively [15]. These results are well consistent with the results of previous reports [19,20]. Similarly, the melting point of ethanol (ET) and 1-butanol (BT) had lower values of $-114 \operatorname{deg} \mathrm{C}$ and $-89 \mathrm{degC}$, respectively. Therefore, blending ET, BT and DDCL with BWCO can potentially enhance the low-temperature flow properties of biodiesel.

\subsection{Low-temperature performance of BWCO blend with ET, BT, and DDCL}

3.2.1 Influence of binary blends on the low-temperature flow properties of BWCO

The influences of blending ET or BT, and DDCL on the CP, CFPP and PP of BWCO are presented in Table 4 .

As shown in Table 4, ET and BT exerted a parallel improvement of the cold flow properties of biodiesel. The PP, CFPP and CP of the binary blends decreased with the increase in the amount of ET and BT. Binary blends of BWCO-BT presented better cold flow properties than those of BWCO-ET. For BWCO-BT blends containing no more than 20 vol.\% BWCO, the CFPP, CP, and PP decreased rapidly with the decrease in the biodiesel content from the initial values of $-8 \operatorname{deg} \mathrm{C},-5 \operatorname{deg} \mathrm{C}$, and $-9 \operatorname{deg} \mathrm{C}$, respectively. 
Table 4 also shows that the cold flow properties of BWCO-ET and BWCO-BT blends are inferior to that of. BWCO-DDCL blends. As the blending DDCL in binary blends was increased to 70 vol.\%, the CFPP decreased by $15 \operatorname{deg} \mathrm{C}, 8 \operatorname{deg} \mathrm{C}$ and $6 \operatorname{deg} \mathrm{C}$ compared to those of pure BWCO, BWCO-ET, and BWCO-BT blends in 30:70 blending ratio, respectively. Further increase in DDCL in BWCO-DDCL blends led to rapid decreases in the values of PP, CFPP, and CP. More amounts of BWCO in blends caused more saturated FAMEs to hinder the low-temperature flow ability of biodiesel blends. However, in the biodiesel blends, the large dissolving capacity of BT and DDCL for the saturated FAMEs notably inhibited the growth of larger wax crystals at freezing cold temperatures.

Table 4 Influence of BWCO-DDCL, BWCO-ET and BWCO-BT binary blends on the CP, CFPP, and PP of BWCO.

\begin{tabular}{|c|c|c|c|c|c|c|c|c|}
\hline $\begin{array}{l}\text { Blend } \\
\text { ratio } \\
\text { (vol.\%) }\end{array}$ & $\begin{array}{l}\text { BWCO- } \\
\text { ET } \\
\text { blends }\end{array}$ & $\begin{array}{l}\text { BWCO- } \\
\text { ET } \\
\text { blends }\end{array}$ & $\begin{array}{l}\text { BWCO- } \\
\text { ET } \\
\text { blends }\end{array}$ & $\begin{array}{l}\text { BWCO- } \\
\text { BT } \\
\text { blends }\end{array}$ & $\begin{array}{l}\text { BWCO- } \\
\text { BT } \\
\text { blends }\end{array}$ & $\begin{array}{l}\text { BWCO- } \\
\text { BT } \\
\text { blends }\end{array}$ & $\begin{array}{l}\text { BWCO- } \\
\text { DDCL } \\
\text { blends } \\
{[15]}\end{array}$ & $\begin{array}{l}\text { BWCO- } \\
\text { DDCL } \\
\text { blends } \\
{[15]}\end{array}$ \\
\hline & $\begin{array}{l}\mathrm{CP} \\
\left({ }^{\circ} \mathrm{C}\right)\end{array}$ & $\begin{array}{l}\text { CFPP } \\
\left({ }^{\circ} \mathrm{C}\right)\end{array}$ & $\begin{array}{l}\mathrm{PP} \\
\left({ }^{\circ} \mathrm{C}\right)\end{array}$ & $\begin{array}{l}\mathrm{CP} \\
\left({ }^{\circ} \mathrm{C}\right)\end{array}$ & $\begin{array}{l}\text { CFPP } \\
\left({ }^{\circ} \mathrm{C}\right)\end{array}$ & $\begin{array}{l}\mathrm{PP} \\
\left({ }^{\circ} \mathrm{C}\right)\end{array}$ & $\begin{array}{l}\mathrm{CP} \\
\left({ }^{\circ} \mathrm{C}\right)\end{array}$ & $\begin{array}{l}\text { CFPP } \\
\left({ }^{\circ} \mathrm{C}\right)\end{array}$ \\
\hline 10:90 & -5 & -7 & -12 & -12 & -14 & -16 & -20 & -22 \\
\hline $20: 80$ & -2 & -4 & -5 & -5 & -8 & -9 & -13 & -15 \\
\hline 30:70 & -1 & -3 & -4 & -3 & -5 & -6 & -10 & -11 \\
\hline 40:60 & 0 & -3 & -4 & -2 & -4 & -6 & -6 & -7 \\
\hline 50:50 & 1 & -2 & -3 & -1 & -4 & -5 & -3 & -5 \\
\hline 60:40 & 2 & -2 & -3 & 0 & -2 & -4 & -2 & -3 \\
\hline 70:30 & 2 & -1 & -2 & 2 & 0 & -2 & -1 & -2 \\
\hline $80: 20$ & 3 & 0 & -1 & 3 & -1 & -2 & 2 & 0 \\
\hline 90:10 & 5 & 1 & 2 & 4 & 0 & 1 & 4 & 3 \\
\hline
\end{tabular}

3.2.2 Influence of ternary blends on the low-temperature flow properties of BWCO

BWCO-ET-DDCL and BWCO-BT-DDCL ternary blends were mixed in specific volume ratios. The comparative results of the PP, CFPP and CP of BWCO-ET-DDCL and BWCO-BT-DDCL ternary blends are presented in Table 5. The bending ratios of these ternary blends are as follows: 5:5:90, 10:10:80, 20:80:0, 20:70:10, 20:60:20, 20:50:30, 20:40:40, 20:30:50, 20:20:60 and 20:10:70.

Table 5 shows that DDCL and ET or BT exerted synergistic effects on enhancing the low-temperature flow properties of biodiesel to a certain degree. Thus, the ternary blending of BWCO and DDCL together with ET or BT resulted in further improvement of the PP, CFPP and CP of BWCO. More importantly, both ET and $\mathrm{BT}$ are bio-based alcohol fuels derived from inexpensive, green, and renewable biomass materials via fermentation method [21-23], thus making these ternary blends environmentally and financially feasible.

However, ternary blends of BWCO-BT-DDCL presented lower CP, CFPP and PP than those of BWCO-ETDDCL. Such result can be attributed to the good intermiscibility of BWCO-BT- DDCL in contrast to that of BWCO-ET-DDCL with identical proportions. When the ternary blends contain $20 \mathrm{vol} \% \mathrm{BWCO}$, the value of CFPP decreased with the increase in the amount of DDCL. As BWCO mixed with BT and DDCL in 20:10:70, 20:20:60, 20:30:50, 20:40:40, and 20:50:30 blending ratios, the CP and CFPP were relatively better than those of BWCO-ET, BWCO-BT and BWCO-DDCL binary blends that contained 20 vol.\% BWCO. $\mathrm{PP}$ also stabilized in the range of $-19{ }^{\circ} \mathrm{C}$ to $-23 \mathrm{degC}$. Notably, BWCO-BT-DDCL ternary blends with the blending ratio of 20:10:70 presented the lowest CP (-17 degC) and CFPP (-19 degC) among the blends with 20 vol.\% biodiesel, PP also decreased to -23 degC. Moreover, the amount of BWCO is still the major factor depressing the low-temperature performance of biodiesel blends. Ternary blends of BWCO-BT-DDCL with blending ratios of 10:10:80 and 5:5:90 presented better cold flow properties, and the CFPP values (-30 degC and $-35 \operatorname{deg}$ ) decreased by $11 \operatorname{degC}$ and $16 \operatorname{deg} \mathrm{C}$ in contrast to those of BWCO-BT-DDCL blends with the 
blending ratio of 20:10:70 (-19 degC), and were also superior to the corresponding binary blends. In other word, the neat BWCO may be unsuitable for using in a low-temperature climate because of the deficiencies of its cold flow properties. Nevertheless, blending DDCL and BT together with BWCO can obviously improve the low-temperature flow properties of biodiesel and widen its temperature ranges for application.

Table 5 Influence of BWCO-ET-DDCL and BWCO-BT-DDCL ternary blends on CP, CFPP, and PP of BWCO.

\begin{tabular}{|c|c|c|c|c|c|c|}
\hline $\begin{array}{l}\text { Blend ratio } \\
\text { (vol.\%) }\end{array}$ & $\begin{array}{l}\text { BWCO-ET- } \\
\text { DDCL } \\
\text { blends } \\
\mathrm{CP}\left({ }^{\circ} \mathrm{C}\right)\end{array}$ & $\begin{array}{l}\text { BWCO-ET- } \\
\text { DDCL } \\
\text { blends } \\
\text { CFPP } \\
\left({ }^{\circ} \mathrm{C}\right)\end{array}$ & $\begin{array}{l}\text { BWCO-ET- } \\
\text { DDCL } \\
\text { blends } \\
\text { PP }\left({ }^{\circ} \mathrm{C}\right)\end{array}$ & $\begin{array}{l}\text { BWCO-BT- } \\
\text { DDCL } \\
\text { blends } \\
\mathrm{CP}\left({ }^{\circ} \mathrm{C}\right)\end{array}$ & $\begin{array}{l}\text { BWCO-BT- } \\
\text { DDCL } \\
\text { blends } \\
\text { CFPP } \\
\left({ }^{\circ} \mathrm{C}\right)\end{array}$ & $\begin{array}{l}\text { BWCO-BT- } \\
\text { DDCL } \\
\text { blends } \\
\text { PP }\left({ }^{\circ} \mathrm{C}\right)\end{array}$ \\
\hline $20: 10: 70$ & -15 & -17 & -21 & -17 & -19 & -23 \\
\hline $20: 20: 60$ & -13 & -16 & -20 & -16 & -18 & -22 \\
\hline $20: 30: 50$ & -13 & -15 & -19 & -15 & -17 & -20 \\
\hline $20: 40: 40$ & -12 & -15 & -18 & -14 & -16 & -20 \\
\hline $20: 50: 30$ & -7 & -14 & -15 & -13 & -16 & -19 \\
\hline $20: 60: 20$ & -6 & -12 & -13 & -11 & -14 & -18 \\
\hline $20: 70: 10$ & -5 & -10 & -11 & -10 & -13 & -14 \\
\hline 10:10:80 & -26 & -28 & -30 & -27 & -30 & -48 \\
\hline $5: 5: 90$ & -30 & -33 & -53 & -33 & -35 & -59 \\
\hline
\end{tabular}

\subsubsection{Ternary phase diagrams of ternary blends on PP, CFPP, and CP}

Ternary phase diagrams were cleverly used to visualize the relationship of $\mathrm{PP}$, CFPP, and CP with the blending ratios of BWCO-ET-DDCL and BWCO-BT-DDCL ternary blends. Isotherms of CFPP, PP and $\mathrm{CP}$ of BWCO-ET-DDCL and BWCO-BT-DDCL systems at temperatures of $0{ }^{\circ} \mathrm{C},-10 \operatorname{deg} \mathrm{C}$, and $-20 \operatorname{degC}$ in the ternary phase diagrams were comparatively investigated and are presented in Figure 3.

Comparative results of BWCO-BT-DDCL (Figs.3B, 3D, and 3F) and BWCO-ET-DDCL (Figs. 3A, 3C, and $3 \mathrm{E}$ ) blends show that BT together with DDCL more effectively improve the PP, CFPP, and CP of biodiesel than ET. The data depicted in Figure 3B show that, when ternary blends contain at least 75 vol.\% BWCO and less than 15 vol.\% BT, their CFPP values are greater than 0 degC. Similarly, blends containing 30 vol.\% to 90 vol.\% BWCO and less than 70 vol.\% DDCL have an excellent CFPP ranging from 0 degC to -10 degC. Both of them occupy relatively narrow ranges of temperature compared with that of BWCO-ET-DDCL. Blends containing 7 vol.\% to 50 vol.\% BWCO and no more than 88 vol.\% DDCL with an excellent CFPP can be used in low temperature areas (-10 degC to $-20 \mathrm{degC})$. Otherwise, better CFPP below -20 degC can be possibly reached for ternary blends containing up to 15 vol.\% BWCO, and such fuels can be used in extremely cold regions of China.

However, Figure 3 also shows that isotherms of PP, CFPP, and CP of BWCO-ET-DDCL and BWCO-BTDDCL ternary blends have similarly varying tendencies. The areas of ternary blends with PP of -20 degC and below are wider than those of $\mathrm{CP}$ and CFPP, whereas the range of $\mathrm{CP}$ (greater than 0 degC) is the widest. Furthermore, the ranges of CP, CFPP, and PP between -10 degC and $0 \operatorname{deg} \mathrm{C}$ constitute the largest areas in the ternary phase diagrams.

Figure 3. Isotherms of CFPP, $\mathrm{PP}$ and $\mathrm{CP}$ of BWCO-ET-DDCL (A, C and E) and BWCO-BT-DDCL (B, $\mathrm{D}$ and $\mathrm{F}$ ) systems at temperatures of $0 \operatorname{deg} \mathrm{C},-10 \operatorname{deg} \mathrm{C}$, and $-20 \operatorname{deg} \mathrm{C}$.

\subsection{Crystallization behavior and crystal morphology observation}

Polarizing optical microscope (POM) has been proven to be an effective technique for observing the crystallization behavior and crystal morphology of sample fuels at low temperature [32-35]. In the POM images, the 
crystals exert polarized reflective light and present bright white images, as well as the amorphous substances absorbed light to form black images [34-36]. The POM images of neat BWCO (100 vol.\% BWCO), BWCO+ DDCL (20 vol.\% BWCO + 80 vol.\% DDCL), BWCO+ET+DDCL (20 vol. $\%$ BWCO + 10 vol. $\%$ ET + 70 vol.\% DDCL) and BWCO+ET+DDCL (20 vol.\% BWCO + 10 vol. $\%$ BT +70 vol.\% DDCL) blends at -15 $\operatorname{deg} \mathrm{C}$ and $-20 \operatorname{deg} \mathrm{C}$ are shown in Figure 4.

As shown in Figure 4, the amounts, sizes, and shapes of wax crystals were varied in neat BWCO, and its blends. In the neat BWCO, the wax crystals have its unique characteristics of large particle sizes, large number and concentrated distribution at the low temperature of $-15 \operatorname{deg} \mathrm{C}$ and $-20 \operatorname{degC}$. The strip-shaped wax crystal were formed in a 3D net structure through cross-linking, and both of them lost their flowability due to the poor low temperature performance $\left(\mathbf{A}_{\mathbf{1}}\right.$ and $\mathbf{A}_{\mathbf{2}}$ ). In the binary blends of BWCO+DDCL, some smaller sized particle-shaped crystals were formed, and the quantity and size of crystals grew as the temperature decreased from $-15 \operatorname{deg} \mathrm{C}$ to $-20 \operatorname{deg} \mathrm{C}\left(\mathbf{B}_{\mathbf{1}}\right.$ and $\left.\mathbf{B}_{\mathbf{2}}\right)$. After blending ET or BT together DDCL with BWCO, distinct differences in the amounts, sizes, and shapes of crystals were noticed (Figs.4C and 4D), and there was an obvious growth in Figure $4\left(\mathbf{C}_{\mathbf{2}}\right)$ and Figure $4\left(\mathbf{D}_{\mathbf{2}}\right)$. Also, the crystals amounts and sizes in BWCO+ET+DDCL and BWCO+BT+DDCL significantly decreased, as well as the distributions of the crystals were more orderly compared to the neat BWCO and BWCO+DDCL blends. As shown in Figure $4 \mathrm{D}$, the morphology of crystals in BWCO+BT + DDC blends were observed in smaller number and sizes than those of BWCO+ET+DDC blends. Such result can be attributed to the large dissolving capacity of BT for alkenes, hydrocarbons, alkanes, cycloalkanes, and aromatic hydrocarbon in DDCL, and different FAMEs are presented in BWCO in contrast to those of ET. In addition, DDCL together with BT acted as an excellent diluent for the high melting compositions of saturated FAMEs that retarded the aggregation and growth of large wax crystals. Thus, the size and number of wax crystal in the BWCO+BT+DDC ternary system were smaller, and could filter through filters easily, providing such ternary blends with better low-temperature flow properties (Figure 4D). 

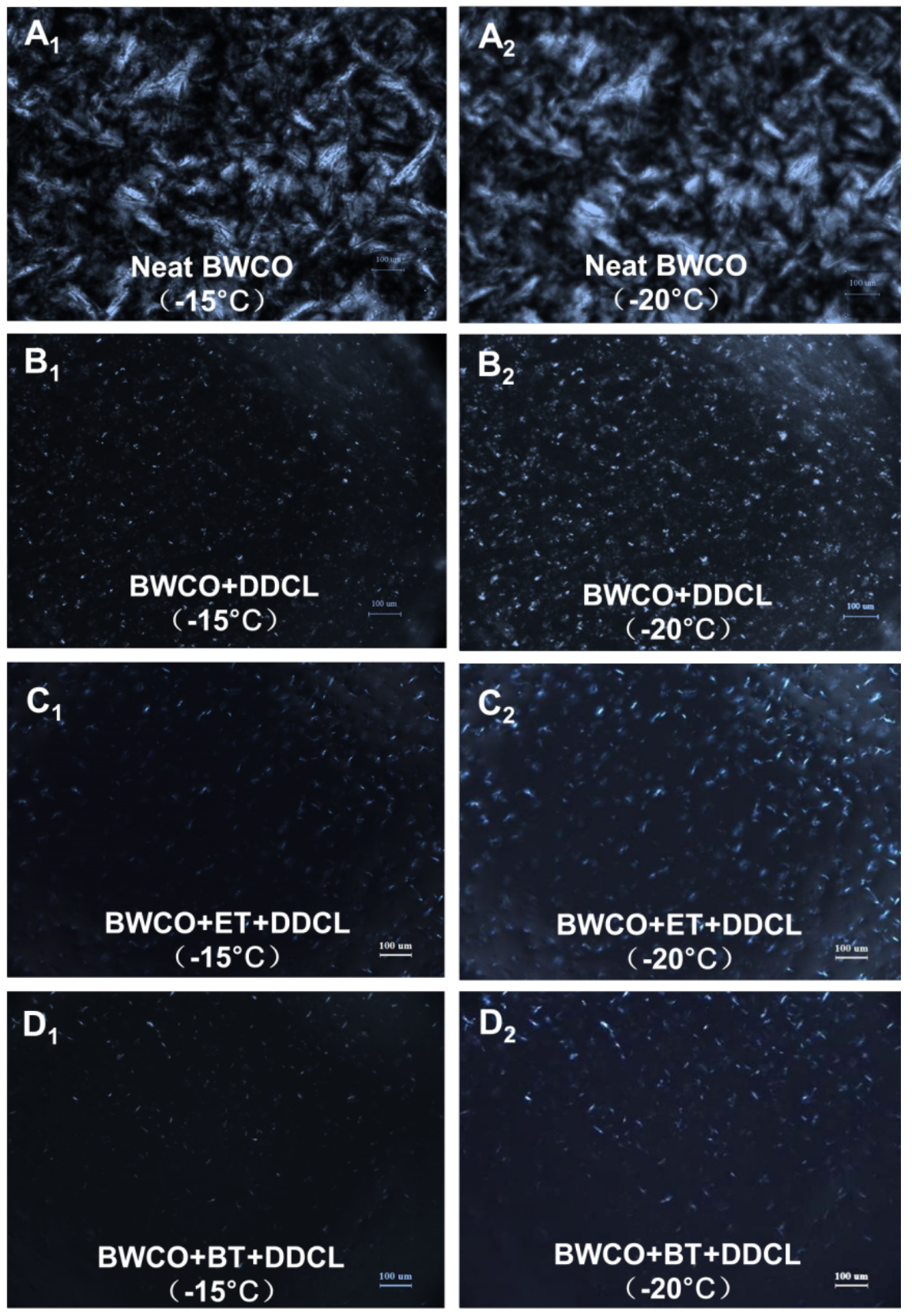

Figure 4. Polarizing optical microscopy images of crystal morphology of neat BWCO, BWCO+ DDCL, $\mathrm{BWCO}+\mathrm{ET}+\mathrm{DDCL}$ and $\mathrm{BWCO}+\mathrm{BT}+\mathrm{DDCL}$ blends at $-15^{\circ} \mathrm{C}$ and $-20 \operatorname{deg} \mathrm{C}$.

\section{Conclusions}

DDCL, ET and BT can significantly enhance the low-temperature flow properties of BWCO. The PP, CFPP and CP of BWCO-ET-DDCL and BWCO-BT-DDCL ternary blends were superior to those of binary biodiesel blends. BT and DDCL present better improvement of the low temperature performance of BWCO as the large dissolving capacity of DDCL and BT for saturated FAMEs in biodiesel retarded the aggregation and growth of large crystals. For ternary blends containing 20 vol.\% BWCO, BWCO-BT-DDCL (20:10:70) 
ternary blends presented the lowest PP, CFPP, and CP with values of $-23 \operatorname{deg} \mathrm{C},-19 \operatorname{deg} \mathrm{C}$, and $-17 \operatorname{deg}$, respectively. Lower CFPP below $-20 \mathrm{degC}$ was possibly reached by BWCO-BT-DDCL blends containing no more than 15 vol.\% BWCO, and such blend fuels can be used in extremely cold regions of China.

\section{Declaration of competing interest}

The authors declare that they have no known competing financial interests or personal relationships that could have appeared to influence the work reported in this paper.

\section{Acknowledgements}

This work was supported from the National Natural Science Foundation of China (Project Number 22008155, 21878188 and 21975161), Chenguang Program of Shanghai Education Development Foundation and Shanghai Municipal Education Commission (Project Number 19CG69).

\section{References}

1. Ambat I, Srivastava V, Sillanpaa M. Recent advancement in biodiesel production methodologies using various feedstock: A review. Renew Sust Energ Rev 2018; 90:356-69.

2. Knothe G. Biodiesel and renewable diesel: a comparison. Prog Energy Combust Sci 2010;36:364-73.

3. Lee AF, Bennett JA, Manayil JC, Wilson K. Heterogeneous catalysis for sustainable biodiesel production via esterification and transesterification. Chem Soc Rev 2014; 43(22):7887-916.

4. Baker M, Bouzidi L, Narine SS. Mitigating crystallization of saturated FAMEs (fatty acid methyl esters) in biodiesel: 2. The phase behavior of 2-stearoyl diolein-methyl stearate binary system. Energy 2015;83:647-57.

5. Mohanan A, Darling B, Bouzidi L, et al. Mitigating crystallization of saturated FAMES (fatty acid methyl esters) in biodiesel. 3. The binary phase behavior of 1, 3-dioleoyl-2-palmitoyl glycerol-Methyl palmitate-A multi-length scale structural elucidation of mechanism responsible for inhibiting FAME crystallization. Energy 2015;86:500-13.

6. Jeong GT, Park JH, Park SH, Park D. Estimating and improving cold filter plugging points by blending biodiesels with different fatty acid contents. Bioresour Technol 2008;13:505-10.

7. Smith PC, Ngothai Y, Nguyen QD, O'Neill BK. Improving the low-temperature properties of biodiesel: methods and consequences. Renew Energ 2010;35:1145-51.

8. Silva L N, Cardoso C C, Pasa V M D. Synthesis and characterization of esters from different alcohols using Macauba almond oil to substitute diesel oil and jet fuel. Fuel 2016; 166: 453-60.

9. Malins K, Kampars V, Kampare R, et al. Properties of rapeseed oil fatty acid alkyl esters derived from different alcohols. Fuel 2014;137:28-35.

10. Nainwal S, Sharma N, Sharma AS, Jain S. Cold flow properties improvement of Jatropha curcas biodiesel and waste cooking oil biodiesel using winterization and blending. Energy 2015;89:702-7.

11. DogVan TH, Temur H. Effect of fractional winterization of beef tallow biodiesel on the cold flow properties and viscosity. Fuel 2013;108:793-6.

12. Xue Y, Zhao Z, Xu G, et al. Effect of poly-alpha-olefin pour point depressant on cold flow properties of waste cooking oil biodiesel blends. Fuel 2016;184:110-7.

13. Madihalli C, Sudhakar H, Doble M. Mannosylerythritol lipid-A as a pour point depressant for enhancing the low temperature fluidity of biodiesel and hydrocarbon fuels. Energ Fuel 2016; 30 (5):4118-25.

14. Su B, Wang L, Xue Y, Yan J, Dong Z, Lin H, Han S. Effect of pour point depressants combined with dispersants on the cold flow properties of biodiesel-diesel blends. J Am Oil Chem Soc 2020; 98(2):163-172.

15. Xue Y, Zhao W, Ma P, Zhao Z, Xu G, Yang C, et al. Ternary blends of biodiesel with petro-diesel and diesel from direct coal liquefaction for improving the cold flow properties of waste cooking oil biodiesel. Fuel 2016;177:46-52.

16. Candeia R A, Silva M C D, Carvalho Filho J R, et al. Influence of soybean biodiesel content on basic properties of biodiesel-diesel blends. Fuel 2009;88(4):738-43.

17. Liu Z, Shi S, Li Y. Coal liquefaction technologies - development in China and challenges in chemical 
reaction engineering. Chem Eng Sci 2010;65:12-7.

18. Liu H, Jiang S, Wang J, Yang C, Guo H, Wang X, et al. Fatty acid esters: a potential cetane number improver for diesel from direct coal liquefaction. Fuel 2015;153:78-84.

19. Wang J, Zhao W, Ai Y, et al. Improving the fuel properties of biodiesel via complementary blending with diesel from direct coal liquefaction. RSC Adv 2015; 5(56):45575-81.

20. Liu H, Jiang S S, Guo H S, et al. A new kind of pour point depressant: Diesel from direct coal liquefaction. Fuel Process Technol 2016;149:285-9.

21. Yuan D, Rao K, Relue P, et al. Fermentation of biomass sugars to ethanol using native industrial yeast strains. Bioresour. Technol. 2011; 102:3246-53.

22. Harun R, Danquah M K, Forde G M. Microalgal biomass as a fermentation feedstock for bioethanol production. J Chem Technol Biotechnol, 2010; 85:199-203.

23. Jang Y S, Lee J, Malaviya A, et al. Butanol production from renewable biomass: rediscovery of metabolic pathways and metabolic engineering. Biotechnol. J.,2012; 7:186-98.

24. Joshi H, Moser B R, Toler J, et al. Effects of blending alcohols with poultry fat methyl esters on cold flow properties. Renew. Energ, 2010; 35:2207-10.

25. Phan A N, Phan T M. Biodiesel production from waste cooking oils. Fuel 2008; 87(17):3490-6.

26. Zhang Y, Dube M A, McLean D D, et al. Biodiesel production from waste cooking oil: 2. Economic assessment and sensitivity analysis. Bioresource technology 2003; 90(3):229-40.

27. Meng X, Chen G, Wang Y. Biodiesel production from waste cooking oil via alkali catalyst and its engine test. Fuel Processing Technology 2008; 89(9):851-57.

28. ASTM D6751, Standard Specification for Biodiesel Fuel Blend Stock (B100) for Middle Distillate Fuels. West Conshohocken (PA): ASTM International; 2015.

29. ASTM D2500. Standard test method for cloud point of petroleum products and liquid fuels. West Conshohocken (PA): ASTM International; 2011.

30. ASTM D6371. Standard test method for cloud point of petroleum products and liquid fuels. West Conshohocken (PA): ASTM International; 2010.

31. ASTM D97. Standard test method for pour point of petroleum products. West Conshohocken (PA): ASTM International; 2012.

32. Yang T, Yin S, Xie M, Chen F, Su B, Lin H, Xue Y, Han S. Effects of N-containing pour point depressants on the cold flow properties of diesel fuel. Fuel 2020; 272:117666.

33. Lin H, Yin S, Su B, Xue Y, Han S. Research on combined-pour point depressant of methacrylateacrylamide copolymers and ethylene-vinyl acetate copolymers for diesel fuel. Fuel 2021; 290(2):120002.

34. Yang T, Wu J, Yuan M, Li X, Yin S, Su B, Yan J, Lin H, Xue Y, Han S. Influence of polar groups on the depressive effects of polymethacrylate polymers as cold flow improvers for diesel fuel. Fuel 2021; 290:120035.

35. Chen F, Liu J, Yang T, Yin S, Xie M, Su B, Dai B, Han S, Xue Y. Influence of maleic anhydride-comethyl benzyl acrylate copolymers modified with long-chain fatty amine and long-chain fatty alcohol on the cold flow properties of diesel fuel. Fuel; 2020, 268,117392.

36. Hamada H, Kato H, N. Ito, Takase Y, Nanbu H., Mishima S., et al. Effects of polyglycerol esters of fatty acids and ethylene-vinyl acetate co-polymer on crystallization behavior of biodiesel. European Journal of Lipid Science and Technology 2010; 112:1323-30. 